\title{
Mouse Genetic Background Influences the Dental Phenotype
}

\author{
Yong Li $i^{a}$ William S. Konicki ${ }^{a}$ J. Timothy Wright ${ }^{b}$ Cynthia Suggs ${ }^{b}$ Hui Xue ${ }^{a, d}$ \\ Melissa A. Kuehl ${ }^{a}$ Ashok B. Kulkarnic Carolyn W. Gibson ${ }^{\mathrm{a}}$ \\ ${ }^{a}$ Department of Anatomy and Cell Biology, School of Dental Medicine, University of Pennsylvania, Philadelphia, Pa., \\ ${ }^{b}$ Department of Pediatric Dentistry, School of Dentistry, University of North Carolina, Chapel Hill, N.C., and \\ 'Functional Genomics Section, Laboratory of Cell and Developmental Biology and Gene Transfer Core, \\ National Institute of Dental and Craniofacial Research, National Institutes of Health, Bethesda, Md., USA; \\ ${ }^{\mathrm{d}}$ Department of Orthodontics, School of Stomatology, Fourth Military Medical University, Xi'an, PR China
}

\section{Key Words}

Genetic background · Enamel · Dentin · Amelogenesis imperfecta · Amelogenin

\begin{abstract}
Dental enamel covers the crown of the vertebrate tooth and is considered to be the hardest tissue in the body. Enamel develops during secretion of an extracellular matrix by ameloblast cells in the tooth germ, prior to eruption of the tooth into the oral cavity. Secreted enamel proteins direct mineralization patterns during the maturation stage of amelogenesis as the tooth prepares to erupt. The amelogenins are the most abundant enamel proteins and are required for normal enamel development. Phenotypic differences were observed between incisors from individual Amelx (amelogenin) null mice that had a mixed $129 \times \mathrm{C} 57 \mathrm{BL} / 6 \mathrm{~J}$ genetic background and between inbred wild-type (WT) mice with different genetic backgrounds (C57BL/6J, C3H/HeJ, FVB/NJ). We hypothesized that this could be due to modifier genes, as human patients with a mutation in an enamel protein gene causing the enamel defect amelogenesis imperfecta (Al) can also have varied appearance of dentitions within a kindred. Enamel density measurements varied for all WT inbred
\end{abstract}

strains midway during incisor development. Enamel thickness varied between some WT strains, and, unexpectedly, dentin density varied extensively between incisors and molars of all WT and Amelx null strains studied. WTFVB/NJ incisors were more similar to those of Amelx null mice than to those of the other WT strains in terms of incisor height/width ratio and pattern of enamel mineralization. Strain-specific differences led to the conclusion that modifier genes may be implicated in determining both normal development and severity of enamel appearance in Al mouse models and may in future studies be related to phenotypic heterogeneity within human Al kindreds reported in the literature.

(c) 2014 S. Karger AG, Basel

\section{Abbreviations used in this paper}

AI amelogenesis imperfecta

AMELX human amelogenin gene on the $\mathrm{X}$ chromosome Amelx murine amelogenin gene on the $\mathrm{X}$ chromosome KO null mutation in mice

MMP20 human matrix metalloproteinase-20 gene Mmp20 murine matrix metalloproteinase-20 gene WT wild-type

\section{KARGER}

E-Mail karger@karger.com www.karger.com/cto (c) 2014 S. Karger AG, Basel

$1422-6405 / 14 / 1986-0448 \$ 39.50 / 0$
Dr. Carolyn W. Gibson

Department of Anatomy and Cell Biology School of Dental Medicine, University of Pennsylvania 240 S. 40th Street, Philadelphia, PA 19104 (USA)

E-Mail cgibson@dental.upenn.edu 


\section{Introduction}

Dental enamel is the highly mineralized tissue that is produced by epithelially derived ameloblast cells and covers the crowns of vertebrate teeth. Early in development, prior to eruption of the tooth into the oral cavity, a single layer of ameloblasts secretes an organic matrix during the secretory stage of amelogenesis [Slavkin et al., 1982; Bei, 2009]. The organic matrix is assembled just after secretion and is processed by proteases secreted by ameloblasts as the enamel rod structures grow and mature [Bartlett, 2013]. Through this process, the ameloblasts determine the intricate organization of developing enamel into rodor prism-shaped structures which have a decussating or crosshatched organization especially visible in rodent teeth [Boyde, 1969]. Most of the cleaved peptides are removed as mineral crystals grow, and finally as the tooth erupts into the oral cavity, only a minor amount of enamel protein remains, which is thought to contribute to the toughness of the mature enamel layer [He and Swain, 2008]. Mature enamel covering the crown of the erupted tooth is the hardest tissue in the human body.

While the organic matrix normally guides organization of the enamel mineralized structures, the process can be interrupted or altered by the presence of abnormal enamel proteins translated from genes with mutations that affect the coding regions [Witkop and Sauk, 1976]. Inherited enamel defects termed amelogenesis imperfecta (AI) have been reported due to mutations in the AMELX (amelogenin), ENAM (enamelin), MMP20 (matrix metalloproteinase-20) and KLK4 (kallikrein 4) genes [Lagerstrom et al., 1991; Rajpar et al., 2001; Hart et al., 2004; Kim et al., 2005; Ozdemir et al., 2005], which encode secreted structural proteins or proteases, and these mutations lead to a deficit in enamel thickness (hypoplasia) or to enamel structural and compositional anomalies (hypocalcification or hypomaturation). Additional gene mutations in FAM83H and WDR72, which encode ameloblast intracellular proteins, are associated with AI [Lee et al., 2008; El-Sayed et al., 2009]. Recently, C4orf26, which encodes a putative extracellular acidic phosphoprotein, and LAMB3, which encodes a protein previously linked to the syndrome junctional epidermolysis bullosa, have been shown to cause AI when mutated [Parry et al., 2012; Kim et al., 2013]. In addition, enamel defects can be part of syndromes including junctional epidermolysis bullosa and tricho-dento-osseous syndrome [Wright et al., 1993, 1997]. Patients with AI can have unsatisfactory esthetics, dental sensitivity and caries due to the enamel structural defects [Markovic et al., 2010].

Genetic Background Affects Murine Teeth
Numerous reports have described phenotypic differences in patients' enamel resulting from mutations in different enamel-related genes [Darling, 1956], and several investigators have reported mutations localized in different regions of the amelogenin gene, encoding the most abundant enamel protein, which alter the respective phenotypes of the defective enamel [Aldred et al., 1992; Lench and Winter, 1995; Wright et al., 2003]. However, differences have also been described between multigenerational family members that presumably have the identical mutation [Rao and Witkop, 1971; Backman and Holmgren, 1988; Lench et al., 1994; Lench and Winter, 1995; Nusier et al., 2004; Wright et al., 2009a], but they could be related to behavior, nutrition or environment. Differences attributed to X-inactivation can explain only mutations in genes located on the $\mathrm{X}$ chromosome, such as AMELX [Witkop and Sauk, 1976; Lench et al., 1994]. Varying phenotypes noted between teeth in individuals with autosomal mutations within a single dentition, between primary and secondary teeth within an affected individual or within individual teeth, as well as the variable presence of AI-associated open bite, are more difficult to explain and have been reported within families with ENAM, FAM83H or other autosomal gene mutations [Witkop and Sauk, 1976; Nusier et al., 2004; Wright et al., 2009a]. Mice with a heterozygous mutation in the Enamelin gene also have varying enamel phenotypes, with nearly normal incisors while molars were discolored and subject to rapid wear [Hu et al., 2008].

To explain this variable phenotype in other tissues, 'modifier genes' had been proposed [Haldane, 1941; Witkop and Sauk, 1971; Genin et al., 2008] and in many cases identified [Nadeau, 2001; Buchner et al., 2003; Hamilton and $\mathrm{Yu}, 2012]$. Modifier genes may act by altering the onset, range of symptoms or clinical severity and have a role in incomplete penetrance [Nadeau, 2003; Tang et al., 2005]. In general, genetic modifiers can function by upor downregulating expression of genes in a particular pathway, or alteration of mRNA stability, DNA methylation or chromatin structure [Linder, 2006].

To better understand whether expression of modifier genes may lead to phenotypic variability in murine teeth, the inbred mouse was chosen for a model, as nondental wild-type (WT) phenotypic and genetic differences between inbred commercially available strains have been documented through genomic DNA sequence determination and the Phenome project [Wade and Daly, 2005]. A major contribution to understanding phenotypic differences between murine teeth was a 2002 report that de- 
scribed levels of susceptibility to dietary fluoride leading to enamel fluorosis, which varied significantly between mouse strains [Everett et al., 2002]. Murine bone has also been shown to be differentially susceptible to fluorosis depending on the strain [Mousny et al., 2006; Everett, 2011]. In untreated WT mice, strain-specific differences between femur size, density and mechanical measures have been reported [Beamer et al., 2002; Wergedal et al., 2005].

Mouse strains have been developed to model the human AI phenotypes by generating null mutations in various enamel protein genes, and the resulting null mice have dental phenotypes similar to human patients with AI [Wright et al., 2009b]. However, we had observed phenotypic differences between individual Amelx null mice that were on a mixed $129 / \mathrm{SvJxC57BL} / 6$ genetic background, as some mice had nearly normal enamel but others had severe enamel defects, and we suspected modifier genes may be responsible. Interestingly, Mmp20 null mice developed a distinctly different enamel appearance when the mutation was transferred to congenic background strains. The C57BL/ 6 congenic Mmp20 null mice have a more severe phenotype compared to REJ129. The prism pattern is less disrupted in the REJ129 mice, and REJ129 enamel has approximately full thickness, rather than being hypoplastic as in the C57BL/6 background [Bartlett J., pers. commun.].

We chose to examine 3 inbred strains for comparison of WT and AI-affected teeth to begin to search for phenotypic differences that could lead to uncovering genes whose expression influences the enamel phenotype. C57BL/6J mice are the most widely used mice for laboratory studies; they are sensitive to fluoride in drinking water and have relatively low bone mineral density [Sacca et al., 2013]. C3H/HeJ mice are considered general purpose lab mice; they are also sensitive to fluoride but have high bone mineral density [Sultzer, 1968]. FVB/NJ mice, which have large pronuclei and large litter sizes so they are frequently used in generation of transgenic mice, are resistant to fluoride and have relatively greater body weight than the other two strains [Taketo et al., 1991; Everett et al., 2002; Wergedal et al., 2005; Everett, 2011]. Each of these inbred strains has been well characterized during development, and in some cases gene mutations or insertions with corresponding pathologies have been identified within the 'WT' strains. In addition, we transferred the Amelx null mutation into these strains in order to examine the consequences for the phenotypes as well as phenotypic differences between inbred and mixed strains.

\section{Materials and Methods}

\section{Murine Models}

WT inbred strains were purchased from Jackson Laboratories (Bar Harbor, Maine, USA), and all procedures were performed in accordance with the regulations of the University of Pennsylvania Institutional Animal Care and Use Committee. Amelx null mice on a $129 \mathrm{SvJxC57BL} / 6 \mathrm{~J}$ genetic background [Gibson et al., 2001] were repeatedly crossed with WTC57BL/6J mice with selection by PCR using tail DNA of mice with the null mutation, as described elsewhere [Li et al., 2008], until greater than generation nine was attained (>99\% congenic). Amelx null C57BL/6J mice were then mated with WTC3H/HeJ or WTFVB/NJ mice to generate F1 hybrids that were mated to generate mixed-background null mice according to the strategy described by Nadeau [2001] in order to examine the phenotypic effect of altered backgrounds. This strategy resulted in 1 or 2 Amelx null pups per litter (25-50\% according to the gender of the null mouse in the first generation, as Amelx is on the X chromosome). PCR was used to establish WT, heterozygous (+/-) or null phenotypes, and weights were determined daily or at the time of euthanasia. Amelx heterozygous female mice were not included in measurements but were initially included as a model of elevated phenotypic heterogeneity in incisor enamel.

\section{Phenotypic Analysis}

Mice ( $n=27-30)$ were weighed for 21 consecutive days, and means were determined. Photographic images were recorded using a Power Shot SX10 IS digital camera (Canon Inc., Toyko, Japan). Mandibular incisor heights were measured from the incisal edge to the gingival margin on the right mandibular incisor using the line tool of ImageJ [Rasband, 2012]. Width measurements were taken between the mandibular midline and the right incisor's distal edge at the intersection of the middle and gingival thirds. Height/width ratios were calculated to standardize photographic images.

\section{MicroCT Analysis for Enamel and Dentin Density}

Mandibles were fixed overnight in $4 \%$ paraformaldehyde and prepared for analysis as described previously [Gibson et al., 2011], except that scans were performed on a microtomograph imaging system ( $\mu$ CT 40, Scanco Medical AG, Brüttisellen, Switzerland) with $16-\mu \mathrm{m}$ resolution at $70 \mathrm{kVp}$ [Pugach et al., 2013]. The images were processed by three-dimensional reconstruction software ( $\mu$ CT Evaluation Program v6.0, Scanco Medical) and analyzed for enamel and dentin density and volume. Hydroxyapatite standards were used for instrument calibration, as described elsewhere [Pugach et al., 2010].

Incisor measurements were analyzed at two locations. The bone barrel is the incisor location as it exits the mandibular bone for eruption, and the molar barrel is the incisor location subjacent to the first mandibular molar as described elsewhere [Gibson et al., 2011]. The first mandibular molar was analyzed at the position over the mesial root apex.

\section{Scanning Electron Microscopy and Enamel Thickness}

Mandibles were fractured using a razor blade, and scanning electron microscopy analysis of fractured internal enamel and dentin surfaces of incisors and molars was carried out at $15 \mathrm{kV}$ on the FEI Quanta 200 FEG (FEI, Hillsboro, Oreg., USA) or using the JEOL JSM T330A scanning electron microscope as described elsewhere [Pugach et al., 2010; Gibson et al., 2011]. 


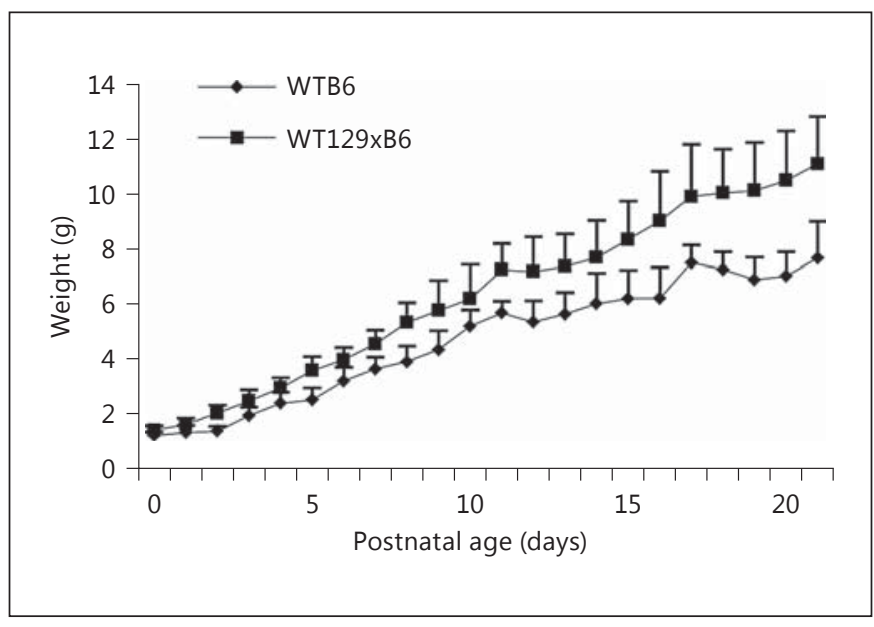

Fig. 1. Mean weights of male and female mice with a C57BL/6J and mixed 129xC57BL/6J genetic background during postnatal days 1-21 (mean of 27-30 mice for each day). On each day, inbred and mixed background mice differed $(\mathrm{p}<0.05)$.

Statistics

Statistical significance for multiple samples was determined by analysis of variance with Bonferroni's multiple comparison test, with significance determined as $\mathrm{p}<0.05$ (GraphPad Prism 5, Graph Pad Software, San Diego, Calif., USA). For analysis of inbred and mixed-background mouse weights, a one-sided Student's $t$ test was used for each time point with significance at $\mathrm{p}<0.05$.

\section{Results}

The common observation that various murine inbred strains have different patterns of weight gain during early development was first confirmed for our mice. The mean weights during the first 3 postnatal weeks of the inbred WTC57BL/6J strain and a WT mixed-background $(129 \times \mathrm{C} 57 \mathrm{BL} / 6 \mathrm{~J})$ strain are shown in figure 1 , where a consistent difference was observed at each time point. $129 \mathrm{xC} 57 \mathrm{BL} / 6 \mathrm{~J}$ is the original genetic background for Amelogenin null (Amelx KO) mice [Gibson et al., 2001].

\section{Incisor Phenotype}

The appearance of the incisors from Amelx null mice shown in figure $2 \mathrm{a}-\mathrm{d}$ illustrates the heterogeneity in appearance that was observed in our colony. These null mice on a 129xC57BL/6J genetic background do not express any of the amelogenin alternatively spliced transcripts that encode amelogenin proteins [Gibson et al., 2001] yet have distinct variations in appearance, which include color and level of chalkiness, tooth shape and amount of attrition. Male and female Amelx null mice had similar levels of phenotypic heterogeneity in incisors. Because some null mice had incisors nearly similar in appearance to those of WT mice, we hypothesized that the variation in the mixed genetic background could be linked to this observation and we therefore transferred the Amelx null mutation to a C57BL/6J background by repeated mating with WTC57BL/6J mice and confirmed the genotype by PCR at each cross until the F9 generation was achieved.

The appearance of WT incisor teeth from different inbred strains was then documented, as phenotypic differences between strains had been reported anecdotally. We found that $\mathrm{C} 57 \mathrm{BL} / 6 \mathrm{~J}$ (fig. 3a) and $\mathrm{C} 3 \mathrm{H} / \mathrm{HeJ}$ (fig. 3b) strains were similar in appearance, but the $\mathrm{FVB} / \mathrm{NJ}$ (fig. 3c) mice had more pigmented incisor teeth with a somewhat different shape. Measurements shown in figure $3 \mathrm{~d}$ are the height/width ratios of mandibular incisors of the $3 \mathrm{WT}$ strains shown in figure $3 \mathrm{a}-\mathrm{c}$ plus the ratios of Amelx null C57BL/6J and null $\mathrm{C} 3 \mathrm{H} / \mathrm{HeJxC} 57 \mathrm{BL} / 6 \mathrm{~J}$ strains for comparison. WTC57BL/6J and WTC3H/HeJ were not statistically different ( $p>0.05)$, while WTFVB/ $\mathrm{NJ}$ and KOC57BL/6J were also similar to each other but different from the other WT strains.

The Amelx null gene on the C57BL/6J background was subsequently transferred to $\mathrm{C} 3 \mathrm{H} / \mathrm{HeJxC} 57 \mathrm{BL} / 6 \mathrm{~J}$ and $\mathrm{FVB} / \mathrm{NJxC57BL/6J}$ backgrounds according to the strategy described by Nadeau [2001], so that effects of the various strains could be determined by more sensitive means such as microCT and scanning electron microscopy.

\section{Incisor Enamel Density}

To better understand the differences between strains, microCT measurements were generated to evaluate the density of enamel and dentin at two locations. Figure 4a shows microCT analysis of WT enamel density in the bone barrel region of incisors for each strain. The bone barrel is located where the incisor exits the mandibular bone at eruption. In this region, the measurement for the 129xC57BL/6J mixed-background mice varied significantly from the $\mathrm{C} 3 \mathrm{H} / \mathrm{HeJ}$ and $\mathrm{FVB} / \mathrm{NJ}$ strains but was similar to C57BL/6J. Figure $4 \mathrm{~b}$ shows density measurements for the incisor molar barrel region, which is a less mature region of incisor enamel inferior to the first molar. The density readings here vary widely with large standard deviations, and a significant difference was observed between $\mathrm{FVB} / \mathrm{NJ}$ and either $\mathrm{C} 57 \mathrm{BL} / 6 \mathrm{~J}$ or $\mathrm{C} 3 \mathrm{H} / \mathrm{HeJ}$ incisor enamel. Examination of the individual measurements led to the realization that the number of zero measurements for enamel density varied between these WT 

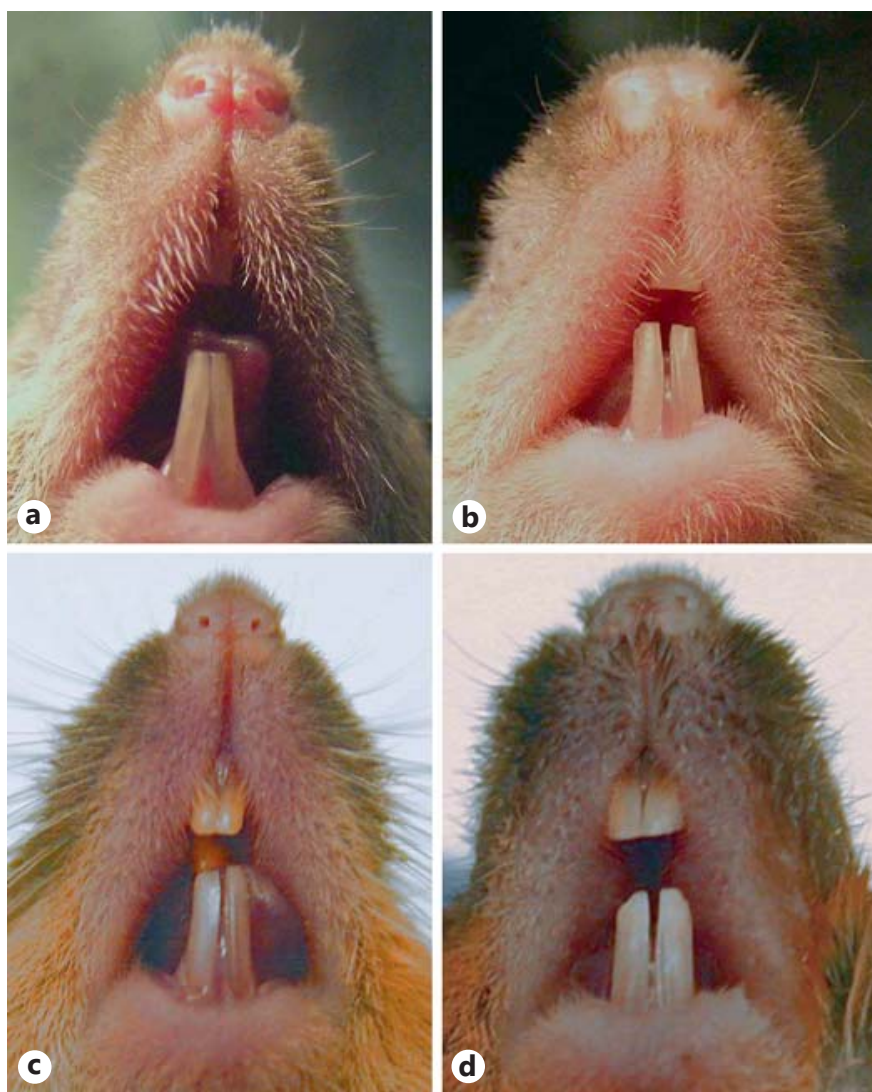

Fig. 2. Images of murine incisors from Amelx null mice with mixed genetic background and phenotypic variability. a Seven-week-old male. b Eight-week-old male. c Six-month-old male. d Six-monthold female.
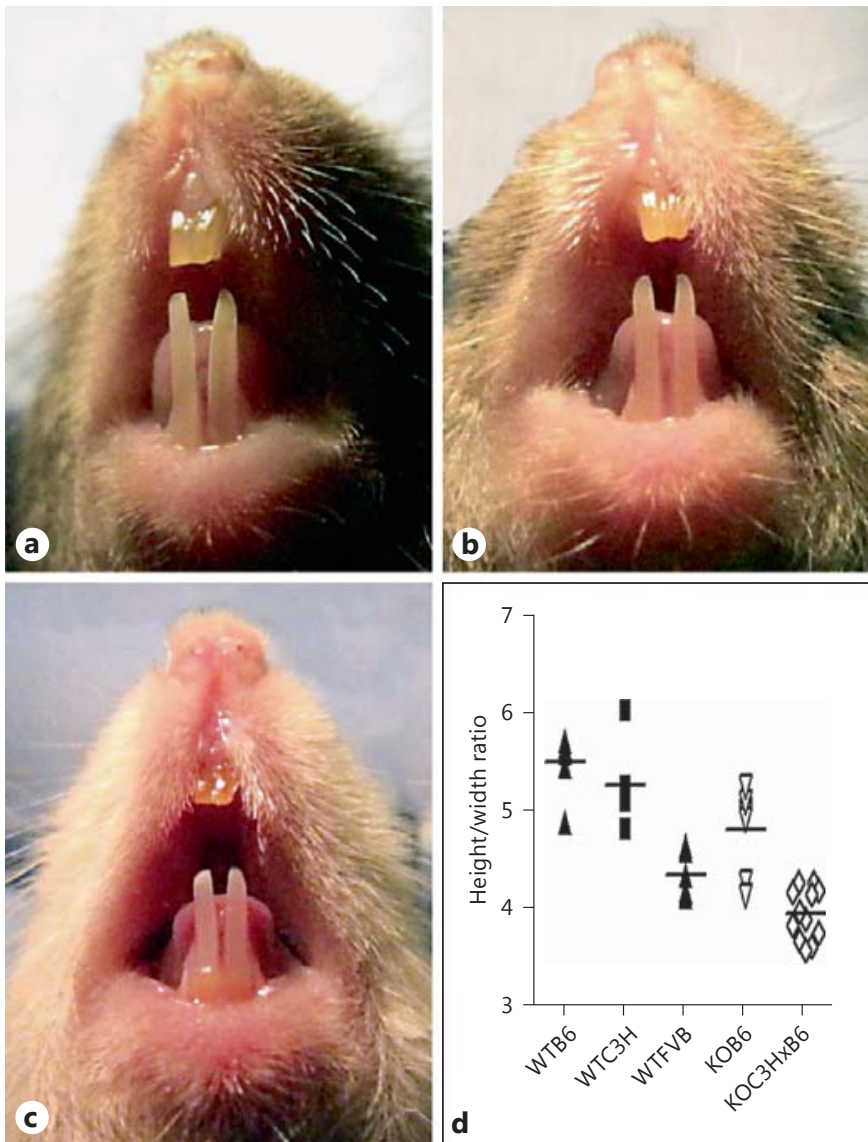

Fig. 3. Images and dimensions of murine incisors from WT strains and Amelx null mice. a WTC57BL/6. b C3H/HeJ. c FVB/NJ. d Ratio of height to width of incisor teeth for the WT strains shown in a-c and KOC57BL/6 and $\mathrm{KOC} 3 \mathrm{H} / \mathrm{HeJxC57BL} / 6$ Amelx null mice $(\mathrm{n}=5-12$ for each group).
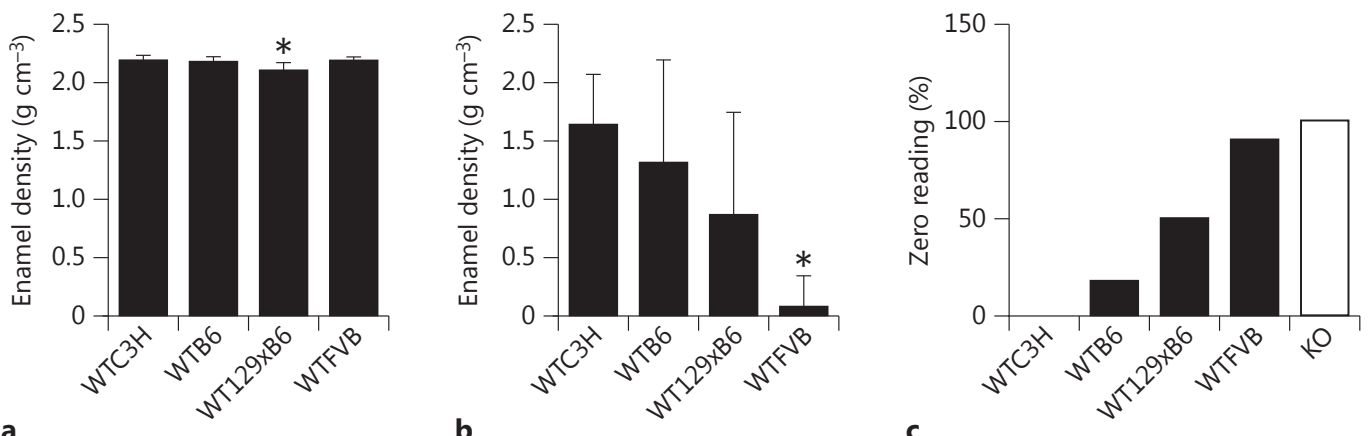

Fig. 4. WT incisor enamel density according to microCT analysis. a Mandibular incisor bone barrel density. ${ }^{*} \mathrm{p}<0.05$ : statistical difference compared to $\mathrm{C} 3 \mathrm{H} / \mathrm{HeJ}$ and FVB/NJ. b Mandibular incisor molar barrel density. ${ }^{*} \mathrm{p}<0.05$ : statistical difference compared to

$\mathrm{C} 3 \mathrm{H} / \mathrm{HeJ}$ and $\mathrm{C} 57 \mathrm{BL} / 6 \mathrm{~J}$. c Percentage of zero microCT enamel readings in the molar barrel region for each WT strain and Amelx null mice. 
strains, and the percentage of samples with zero measurements is plotted in figure $4 \mathrm{c}$. While there were no zero measurements for $\mathrm{C} 3 \mathrm{H} / \mathrm{HeJ}$ incisors, the number of zero measurements increased to $20 \%$ for C57BL/6J, 50\% for mixed 129xC57BL/6J background and nearly $100 \%$ for $\mathrm{FVB} / \mathrm{NJ}$ mice. The Amelx null mice were used as a control as they generally do not have mineral at this location of the incisor during development. A comparison of figure $4 \mathrm{a}$ and $\mathrm{b}$ shows that the delay in incisor enamel mineralization observed in WTFVB/NJ mice seems to recover by the time the tooth erupts.

For each strain, the mean density of incisor enamel was greater at the mandibular bone barrel location compared to the molar barrel site. This increased density at the bone barrel would be expected, as during normal development, the enamel increases in mineral content as the tooth moves toward eruption. Molar barrel enamel in the incisor was also invariably less dense compared to molar tooth enamel (data not shown).

\section{Enamel Thickness}

Because the enamel layer in Amelx null mice is too thin to measure accurately by microCT, scanning electron microscopy images were used to measure enamel thickness in the various WT and Amelx null murine strains. Significant differences in enamel thickness were noted between WTC57BL/6J and WTFVB/NJ or WT129xC57BL/6J mice for incisors and between C57BL/6J and FVB/NJ mice for molars (fig. 5a, b). Although there was variability, significant differences were not observed between the thickness of incisor and molar enamel in any of the strains of Amelx null mice, perhaps because the mixed genetic background strains all contained C56BL/6 (fig. 5c, d). For each WT strain, incisor enamel had greater thickness than the thickest region of molar enamel $(\mathrm{p}<0.05)$.

\section{Dentin Density}

Using microCT, dentin density was also evaluated in the individual strains for WT and Amelx null mice. For WT strains, the dentin differed in density in the mixed 129xC57BL/6J background mice from any of the 3 inbred strains at the bone barrel location (fig. 6a), as well as for molar dentin (fig. 6c). At the molar barrel location of the incisor, dentin varied from mixed $129 \times \mathrm{xC} 57 \mathrm{BL} / 6 \mathrm{~J}$ background mice for both $\mathrm{C} 57 \mathrm{BL} / 6 \mathrm{~J}$ and $\mathrm{C} 3 \mathrm{H} / \mathrm{HeJ}$ (fig. 6b). Significant differences between dentin density in the Amelx null mice were noted for C57BL/6 (fig. 6d), while all strains varied in dentin density at the molar barrel location in incisors and in molars (fig. 6e, f).

Genetic Background Affects Murine Teeth

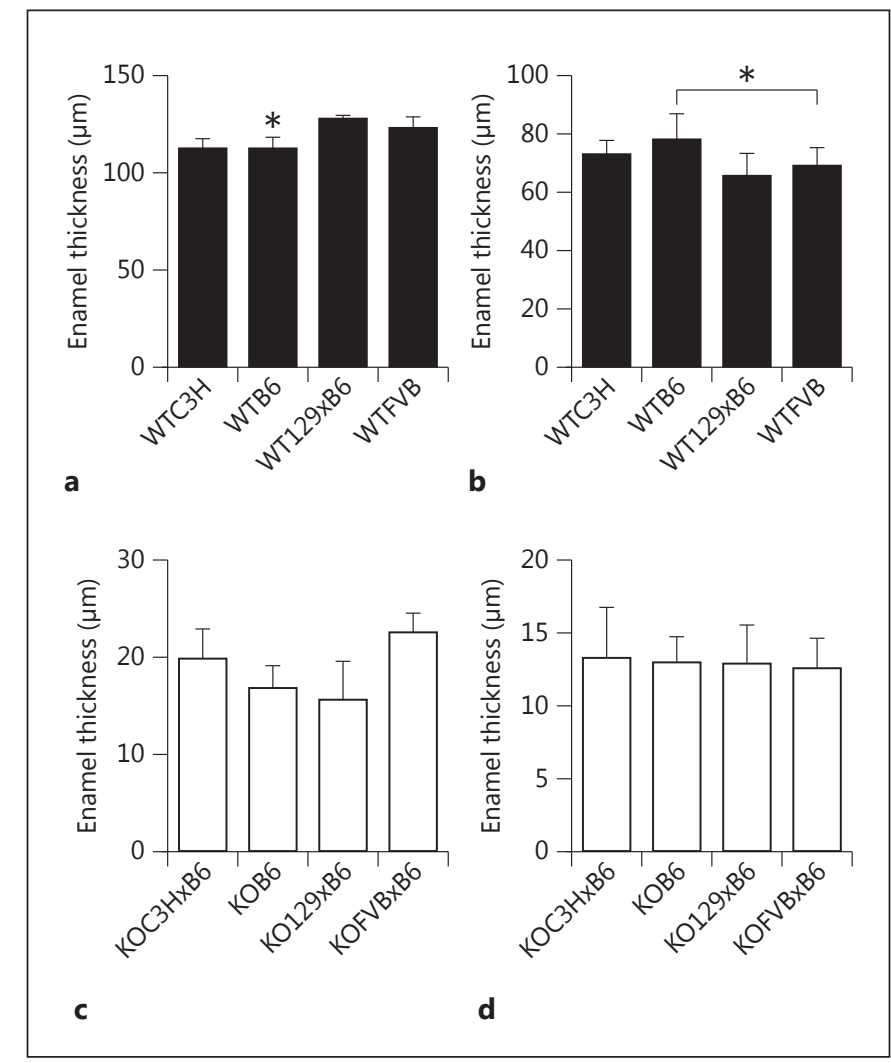

Fig. 5. Enamel thickness by scanning electron microscopy. a WT incisors. * Statistically different from WT129xB6 and WTFVB $(\mathrm{p}<0.05)$. b WT molars. * Statistically different $(\mathrm{p}<0.05)$. c Amelx null incisors. d Amelx null molars. c, d Differences not noted.

\section{Discussion}

The AI inherited enamel defect has a heterogeneous phenotype in human patients, which is due partly to mutations in different enamel protein genes or mutations in different domains of a single enamel protein gene. Xlinked mutations may also lead to heterogeneity due to potential lyonization of $\mathrm{X}$ chromosomal genes during enamel development. Yet another level of phenotypic difference has been mentioned repeatedly in the literature in both human kindreds and in mice, which may be attributed to the effects of modifier genes active in ameloblasts during enamel formation.

WT inbred strains are known to differ from each other with regard to various parameters during development and in adult mice [Linder, 2006; Taft et al., 2006], and we therefore chose 3 commonly studied but somewhat dissimilar inbred mouse strains to evaluate in order to detect significant differences. In various studies, inbred mouse 


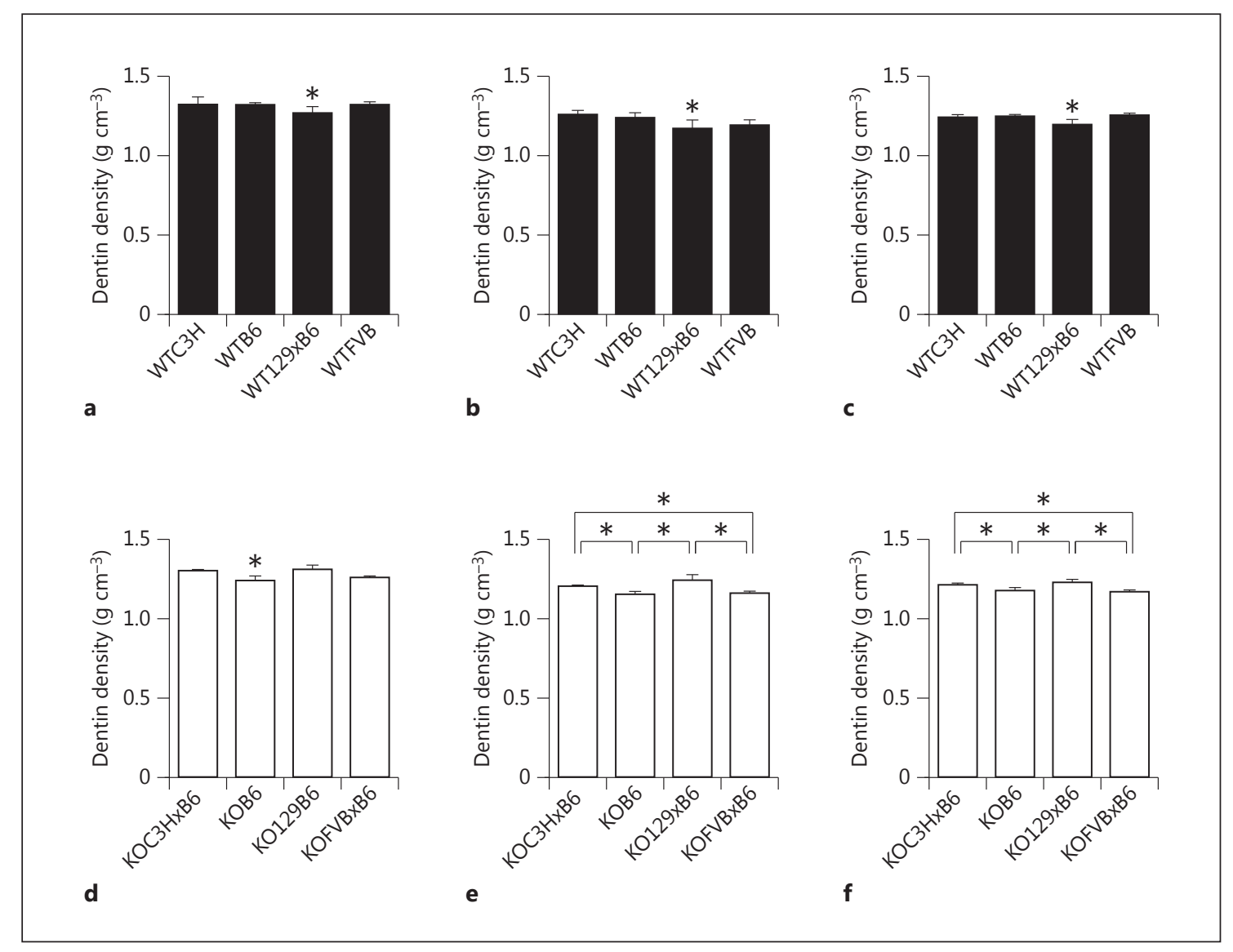

Fig. 6. Dentin density measured by microCT. a WT incisors in the bone barrel region. * Statistically different from the 3 inbred strains $(\mathrm{p}<0.05)$. b WT incisors in the molar barrel region. * Statistically different from $\mathrm{C} 3 \mathrm{H} / \mathrm{HeJ}$ and $\mathrm{C} 57 \mathrm{BL} / 6(\mathrm{p}<0.01)$. c WT molars.
* Statistically different from the 3 inbred strains $(\mathrm{p}<0.01)$. d Amelx null incisors in the bone barrel region. * Statistically different from $\mathrm{C} 3 \mathrm{H} / \mathrm{HeJxB6}$ and C57BL/6x129 (p < 0.01). e Amelx null incisors in the molar barrel region $(\mathrm{p}<0.05)$. $f$ Amelx null molars $(\mathrm{p}<0.01)$. strains have been reported to vary significantly from each other in terms of weight, developmental timing, size and bone density, among other factors, and in relation to the effects of genetic mutations. In this study, all mice were treated identically, including availability and type of chow, vivarium humidity, temperature and light and dark cycles, and all were similar ages when analyzed. Nevertheless, differences in the appearance of Amelx null incisors in mice with a mixed genetic background were obvious, leading us to predict a modifier gene or other source of genotypic difference. These differences were not due to X-chromosomal lyonization, as heterozygous females were not included in the comparison.

Transgenic or null mice generated with mixed genetic backgrounds may be expected to demonstrate greater phenotypic heterogeneity than inbred strains, and the Jackson Laboratory has recommended that these muta- tions be constructed in mice with a well-defined strain background such as C57BL/6J or FVB/NJ [Linder, 2006]. We noted that the WTFVB/NJ strain has several features more consistent with an Amelx null phenotype, including incisor height/width ratio (compared to KOC57BL/6 or $\mathrm{KOC} 3 \mathrm{H} / \mathrm{HeJ} / \mathrm{C} 56 \mathrm{BL} / 6$ ) and incisor molar barrel density (all KO strains), while appearance and microCT analyses of WTC3H/HeJ and WTC57BL/6J strains are more similar to each other. The finding of differences between incisor and molar dentin density for most of the WT and Amelx null strains was somewhat surprising; variability between WT dental phenotypes can complicate analysis of the effects of null mutations or transgenic expression on these backgrounds.

Heterogeneity in human phenotypes due to mutations leading to the various forms of AI has frequently been commented upon, related to differences within and be- 
tween individual teeth in a patient, between primary and secondary dentition and between affected members of a single kindred. Lyonization, the inactivation of one of the $\mathrm{X}$ chromosomes in females, can explain heterogeneity in females with X-linked disease [Nadeau, 2001], but mutations in autosomal genes cannot be explained in this way. The variability of the phenotypes in Amelx null mice on a mixed genetic background is associated with the genes of two parents which segregate randomly between offspring, when only male mice are compared to avoid the lyonization effect. Understanding the potential impact of genetic modifiers which vary according to murine strain can shed light on genetic networks which have potential for manipulation for therapeutic intervention [Hamilton and $\mathrm{Yu}, 2012]$.

Phenotypic differences can result from regulation of timing or level of expression of proteins important to ameloblast differentiation or enamel development, from availability of precursors of the mineral phase or from factors related to general growth characteristics. Susceptibility to environmental fluoride varies tremendously in the human populations as does the mineral density of hard tissues. Discovery of genetic causes for phenotypic differences between WT strains or strains with identical mutations but different genetic backgrounds will eventu- ally lead to a more complete picture of forces important for generation or regeneration of tissues such as enamel, which for humans must last from eruption of the secondary teeth into the oral cavity until the end of life, and have the potential to lead to therapeutic intervention in order to save a tooth. This work can lead toward a future goal of identifying the modifier genes that contribute to these phenotypes through tweaking levels of expression of target genes [Bandiera et al., 2010], e.g. by altering expression of transcription factors, miRNA or alterations within physiologically important pathways that direct development of the mineralized tissues in the tooth. A fuller understanding may lead to new insights into mechanisms involved in tooth regeneration and aid in maintaining the dentition throughout adulthood.

\section{Acknowledgements}

We acknowledge and thank J. Bartlett for communicating unpublished data and thank M. Pugach, E. Everett and J. Li for discussions of the data and concepts. We appreciate the care provided by the Penn Dental Medicine vivarium staff. This work was supported by funding from the National Institute of Dental Research (R01-DE011089).

\section{References}

Aldred, M.J., P.J.M. Crawford, E. Roberts, C.M. Gillespie, N.S.T. Thomas, I. Fenton, L.A. Sandkuul, P.S. Harper (1992) Genetic heterogeneity in X-linked amelogenesis imperfecta. Genomics 14: 567-573.

Backman, B., G. Holmgren (1988) Amelogenesis imperfecta: a genetic study. Hum Hered 38: 189-206.

Bandiera, S., E. Hatem, M.S. Lyonnet, A. Henrion-Caude (2010) microRNAs in diseases: from candidate to modifier genes. Clin Genet 77: 306-313.

- Bartlett, J.D. (2013) Dental enamel development: proteinases and their enamel matrix substrates. ISRN Dent 2013: 684607.

Beamer, W.G., L.R. Donahue, C.J. Rosen (2002) Genetics and bone. Using the mouse to understand man. J Musculoskelet Neuronal Interact 2: 225-231.

Bei, M. (2009) Molecular genetics of ameloblast cell lineage. J Exp Zool B Mol Dev Evol 312B: 437-444.

Boyde, A. (1969) Electron microscopic observations relating to the nature and development of prism decussation in mammalian dental enamel. Bull Group Int Rech Sci Stomatol 12: 151-207.
Buchner, D.A., M. Trudeau, M.H. Meisler (2003) SCNM1, a putative RNA splicing factor that modifies disease severity in mice. Science 301: 967-969.

Darling, A.I. (1956) Some observations on amelogenesis imperfecta and calcification of the dental enamel. Proc Royal Soc Med 49: 39-45.

El-Sayed, W., D.A. Parry, R.C. Shore, M. Ahmed, H. Jafri, Y. Rashid, S. Al-Bahlani, A. Al Harasi, J. Kirkham, C.F. Inglehearn, A.J. Mighell (2009) Mutations in the beta propeller WDR72 cause autosomal-recessive hypomaturation amelogenesis imperfecta. Am J Hum Genet 85: 699-705.

Everett, E. (2011) Fluoride's effects on the formation of teeth and bones, and the influence of genetics. J Dent Res 90: 552-560.

Everett, E.T., M.A.K. McHenry, N. Reynolds, H. Eggertsson, J. Sullivan, C. Kantmann, E.A. Martinez-Mier, J.M. Warrick, G.K. Stookey (2002) Dental fluorosis: variability among different inbred mouse strains. J Dent Res 81 : 794-798.

Genin, E., J. Feingold, F. Clerget-Darpoux (2008) Identifying modifier genes of monogenic disease: strategies and difficulties. Hum Genet 124: $357-368$.
Gibson, C.W., Y. Li, C. Suggs, M.A. Kuehl, M.K Pugach, A.B. Kulkarni, J.T. Wright (2011) Rescue of the murine amelogenin null phenotype with two amelogenin transgenes. Eur J Oral Sci 119(suppl 1): 70-74.

Gibson, C.W., Z.A. Yuan, B. Hall, G. Longenecker, E. Chen, T. Thyagarajan, T. Sreenath, J.T. Wright, S. Decker, R. Piddington, G. Harrison, A.B. Kulkarni (2001) Amelogenin-deficient mice display an amelogenesis imperfecta phenotype. J Biol Chem 276: 31871-31875.

Haldane, J.B.S. (1941) The relative importance of principal and modifying genes in determining some human diseases. J Genet 41: 149157.

Hamilton, B.A., B.D. Yu (2012) Modifier genes and the plasticity of genetic networks in mice. PLoS Genet 8: e1002644.

Hart, P.S., T.C. Hart, M.D. Michalec, O.H. Ryu, D. Simmons, S. Hong, J.T. Wright (2004) Mutation in kallikrein 4 causes autosomal recessive hypomaturation amelogenesis imperfecta. J Med Genet 41: 545-549.

He, L.H., M.V. Swain (2008) Understanding the mechanical behavior of human enamel from its structural and compositional characteristics. J Mech Behav Biomed Mater 1: 18-29.
Genetic Background Affects Murine

Teeth
Cells Tissues Organs 2013;198:448-456 DOI: 10.1159/000360157 
Hu, J.C.C., Y. Hu, C.E. Smith, M.D. McKee, J.T. Wright, Y. Yamakoshi, P. Papagerakis, G.K. Hunter, J.Q. Feng, F. Yamakoshi, J.P. Simmer (2008) Enamel defects and ameloblast-specific expression in Enam knock-out/lacZ knockin mice. J Biol Chem 283: 10858-10871.

Kim, J.W., F. Seymen, K.E. Lee, J. Ko, M. Yildirim, E.B. Tuna, K. Gencay, T.J. Shin, H.K. Kyun, J.P. Simmer, J.C.C. Hu (2013) LAMB3 mutations causing autosomal-dominant amelogenesis imperfecta. J Dent Res 92: 899-904.

Kim, J.W., J.P. Simmer, T.C. Hart, P.S. Hart, M.D. Ramaswami, J.D. Bartlett, J.C.C. Hu (2005) MMP-20 mutation in autosomal recessive pigmented hypomaturation amelogenesis imperfecta. J Med Genet 42: 271-275.

Lagerstrom, M., N. Dahl, Y. Nakahori, Y. Nakagome, B. Backman, U. Landegren, U. Pettersson (1991) A deletion in the amelogenin gene (AMG) causes X-linked amelogenesis imperfecta (AIH1). Genomics 10: 971-975.

Lee, S.-K., J.C.C. Hu, J.D. Bartlett, K.-E. Lee, B.P.-J. Lin, J.P. Simmer, J.W. Kim (2008) Mutational spectrum of FAM83H: the C-terminal portion is required for tooth enamel calcification. Hum Mutat 29: E95-E99.

Lench, N.J., A.H. Brook, G.B. Winter (1994) SSCP detection of a nonsense mutation in exon 5 of the amelogenin gene (AMG) causing $\mathrm{X}$ linked amelogenesis imperfecta (AIH1). Hum Mol Genet 3: 827-828.

Lench, N.J., G.B. Winter (1995) Characterisation of molecular defects in X-linked amelogenesis imperfecta (AIH1). Hum Mutat 5: 251-259.

Li, Y., C. Suggs, J.T. Wright, Z.A. Yuan, M. Aragon, H. Fong, D. Simmons B. Daly, E.E. Golub, G. Harrison, A.B. Kulkarni, C.W. Gibson (2008) Partial rescue of the amelogenin null dental enamel phenotype. J Biol Chem 283: 15056-15062.

Linder, C.C. (2006) Genetic variables that influence phenotype. ILAR J 47: 132-140.

Markovic, D., B. Petrovic, T. Peric (2010) Case series: clinical findings and oral rehabilitation of patients with amelogenesis imperfecta. Eur Arch Paediatr Dent 11: 201-208.

Mousny, M., X. Banse, L. Wise, E.T. Everett, R. Hancock, R. Vieth, J.P. Devogelaer, M.D. Grynpas (2006) The genetic influence on bone susceptibility to fluoride. Bone 39 : 1283-1289.

Nadeau, J.H. (2001) Modifier genes in mice and humans. Nat Rev Genet 2: 165-174.

Nadeau, J.H. (2003) Modifier genes and protective alleles in humans and mice. Curr Opin Genet Dev 13: 290-295.
Nusier, M., O. Yassin, T.C. Hart, A. Samimi, J.T. Wright (2004) Phenotypic diversity and revision of the nomenclature for autosomal recessive amelogenesis imperfecta. Oral Surg Oral Med Oral Pathol Oral Radiol Endod 97: 220230.

Ozdemir, D., P.S. Hart, O.H. Ryu, S.J. Choi, M. Ozdemir-Karatas, E. Firatli, N. Piesco, T.C. Hart (2005) MMP20 active-site mutation in hypomaturation amelogenesis imperfecta. J Dent Res 84: 1031-1035.

Parry, D.A., S.J. Brookes, C.V. Logan, J.A. Poulter, W. El-Sayed, S. Al-Bahlani, S. Al Harasi, J. Sayed, M. Raif el, R.C. Shore, M. Dashash, M. Barron, J.E. Morgan, I.M. Carr, G.R. Taylor, C.A. Johnson, M.J. Aldred, M.J. Dixon, J.T. Wright, J. Kirkham, C.F. Inglehearn, A.J. Mighell (2012) Mutations in C4orf26, encoding a peptide with in vitro hydroxyapatite crystal nucleation and growth activity, cause amelogenesis imperfects. Am J Hum Genet 91: 565-571.

Pugach, M.K., Y. Li, C. Suggs, J.T. Wright, M.A. Aragon, Z.A. Yuan, D. Simmons, A.B. Kulkarni, C.W. Gibson (2010) The amelogenin Cterminus is required for enamel development. J Dent Res 89: 165-169.

Pugach, M.K., C. Suggs, Y. Li, J.T. Wright, A.B. Kulkarni, J.D. Bartlett, C.W. Gibson (2013) M180 amelogenin processed by MMP20 is sufficient for decussating murine enamel. J Dent Res 92: 1118-1122.

Rajpar, M.H., K. Harley, C. Laing, R.M. Davies, M.J. Dixon (2001) Mutation of the gene encoding the enamel-specific protein, enamelin, causes autosomal-dominant amelogenesis imperfecta. Hum Mol Genet 10: 1673-1677.

Rao, S., C.J. Witkop, Jr. (1971) Inherited defects in tooth structure. Birth Defects Orig Artic Ser 7: 153-184.

Rasband, W.S. (1997-2012) Image J. Bethesda, US National Institutes of Health. http://imageJ.nih.gov/ij/.

Sacca, R., B. Elder, K. Wasson (2013) The C57BL/6 mouse. White Paper. Charles River Laboratories International. http://www.criver.com/ files/pdfs/rms/c57bl6/rm_rm_r_c57bl6_ white_paper.aspx.

Slavkin, H.C., M. Zeichner-David, M. MacDougall, C. Bessem, P. Bringas, L.S. Honig, J. Lussky, J. Vides (1982) Enamel gene products during murine amelogenesis in vivo and in vitro. J Dent Res Spec No: 1467-1471.

Sultzer, B.M. (1968) Genetic control of leukocyte responses to endotoxin. Nature 219: 12531254.
Taft, R.A., M. Davisson, M.V. Wiles (2006) Know thy mouse. Trends Genet 22: 649-653.

Taketo, M., A.C. Schroeder, L.E. Mobraaten, K.B. Gunning, G. Hanten, R.R. Fox, T.H. Roderick, C.L. Stewart, F. Lilly, C.T. Hansen, P.A. Overbeek (1991) FVB/N: an inbred mouse strain preferable for transgenic analyses. Proc Natl Acad Sci USA 88: 2065-2069.

Tang, Y., K.S. Lee, H,T. Yang, D.W. Logan, S. Wang, M.L. McKinnon, L.J. Holt, A. Condie, M.T. Luu, R.J. Akhurst (2005) Epistatic interactions between modifier genes confer strainspecific redundancy for Tgfbl in developmental angiogenesis. Genomics 85: 60-70.

Wade, C.M., M.J. Daly (2005) Genetic variation in laboratory mice. Nat Genet 37: 1175-1180.

Wergedal, J.E., M.H-C. Sheng, C.L. Ackert-Bicknell, W.G. Beamer, D.J. Baylink (2005) Genetic variation in femur extrinsic strength in 29 different inbred strains of mice is dependent on variations in femur cross-sectional geometry and bone density. Bone 36: 111-122.

Witkop, C.J., J.J. Sauk (1971) Dental and Oral Manifestations of Hereditary Disease. New York, American Academy of Oral Pathology.

Witkop, C.J., J.J. Sauk (1976) Heritable defects of enamel; in Stewart, R.E., G.H. Prescott (eds): Oral Facial Genetics. St. Louis, Mosby, pp 151-226.

Wright, J.T., J.D. Fine, L.B. Johnson (1993) Development defects of enamel in humans with hereditary epidermolysis bullosa. Arch Oral Biol 38: 945-955.

Wright, J.T., S. Frazier-Bowers, D. Simmons, K. Alexander, P. Crawford, S.T. Han, P.S. Hart, T.C. Hart (2009a) Phenotypic variation in FAM83H-associated amelogenesis imperfecta. J Dent Res 88: 356-360.

Wright, J.T., P.S. Hart, M.J. Aldred, K. Seow, P.J. Crawford, S.P. Hong, C.W. Gibson, T.C. Hart (2003) Relationship of phenotype and genotype in X-linked amelogenesis imperfecta. Connect Tissue Res 44(suppl 1): 72-78.

Wright, J.T., T.C. Hart, P.S. Hart, D. Simmons, C. Suggs, B. Daley, J. Simmer, J. Hu, J.D. Bartlett, Y. Li, Z.A. Yuan, W.K. Seow, C.W. Gibson (2009b) Human and mouse enamel phenotypes resulting from mutation or altered expression of AMEL, ENAM, MMP20 and KLK4. Cells Tissues Organs 189: 224-229.

Wright, J.T., K. Kula, K. Hall, J.H. Simmons, T.C. Hart (1997) Analysis of the tricho-dento-osseous syndrome genotype and phenotype. Am J Med Genet 72: 197-204. 